\title{
Markov Chain Analysis and Student Academic Progress: An Empirical Comparative Study
}

Shafiqah Alawadhi

Kuwait University, alawadhidodo@yahoo.com

Mokhtar Konsowa

Kuwait University, mokhtar@stat.kuniv.edu

Follow this and additional works at: http://digitalcommons.wayne.edu/jmasm

Part of the Applied Statistics Commons, Social and Behavioral Sciences Commons, and the Statistical Theory Commons

\section{Recommended Citation}

Alawadhi, Shafiqah and Konsowa, Mokhtar (2010) "Markov Chain Analysis and Student Academic Progress: An Empirical Comparative Study," Journal of Modern Applied Statistical Methods: Vol. 9 : Iss. 2 , Article 26.

DOI: $10.22237 /$ jmasm/1288585500

Available at: http://digitalcommons.wayne.edu/jmasm/vol9/iss2/26

This Regular Article is brought to you for free and open access by the Open Access Journals at DigitalCommons@WayneState. It has been accepted for inclusion in Journal of Modern Applied Statistical Methods by an authorized editor of DigitalCommons@WayneState. 


\title{
Markov Chain Analysis and Student Academic Progress: An Empirical Comparative Study
}

\author{
Shafiqah Alawadhi Mokhtar Konsowa \\ Kuwait University
}

An application of Markov Chain Analysis of student flow at Kuwait University is presented based on a random sample of 1,100 students from the academic years 1996-1997 to 2004-2005. Results were obtained for each college and in total which allows for a comparative study. The students' mean lifetimes in different levels of study in the colleges as well as the percentage of dropping out of the system are estimated.

Key words: Absorbing Markov chains, transition probabilities; absorbing state.

\section{Introduction}

The realization of the importance of education has increased among the public in Kuwait, and as a result, the traditional formal education has changed in recent years. To compete in the world market, nations are giving priority to higher education for the purpose of preparing students to be capable to bear the responsibility. Higher educational institutions in the state of Kuwait have encountered challenges in recent years. The economic and social needs associated with higher educational

Shafiqah Alawadhi is an Associate Professor in the Department of Statistics \& Operations Research, Kuwait University. She received her $\mathrm{Ph}$. D. from the Department of Mathematics, Aberdeen University, Scotland, UK. Her research interests include General Statistical Analysis, Bayesian Statistics especially Subjective Probability Assessment and Environmental Statistics. Email her at: alawadhidodo@yahoo.com. Mokhtar Konsowa is an Associate Professor in the Department of Statistics \& Operations Research, Kuwait University. He received his $\mathrm{Ph}$. D. from the Department of Mathematics, University of Cincinnati, USA. His research interests are in Probability and Stochastic Processes and focus on the area of random walks on graphs. Email him at: mokhtar@stat.kuniv.edu. institutions have attracted the attention of many segments of the Kuwaiti public to observe the performance of these organizations with renewed and increased interest. The financial burden on the government to support higher educational institutions in Kuwait increases the responsibility of the institutions to maintain their efficiency. Kuwait University (KU) consists of 13 colleges which follow a regular semester system, with the exceptions of the Medical Sciences and Law colleges, which follow an annual system. Each semester consists of approximately 16 weeks and each year includes two semesters: Fall (September January) and Spring (February - June). KU also offers a summer semester that is not compulsory; however, about $65 \%$ of students take summer courses. A typical student takes about 4 years to complete the required credit hours; students of Engineering and the Medical $\mathrm{S}$ ciences colleges are exceptions and they take slightly longer to complete the credit hours. The required numbers of credit hours to graduate from the different colleges are:

1. Allied Health, Social Sciences, Science and Business Administration: 126 to 130 credit hours.

2. Arts and Education: 132 credit hours.

3. Sharia \& Islamic Studies: 142 credit hours.

4. Engineering and Petroleum: 144 credit hours. 


\section{ALAWADHI \& KONSOWA}

5. Medical Sciences (Pharmacy - 5 yrs; Dentistry - 6 yrs; Medicine - 7 yrs; annual system).

6. Law (4 yrs; annual system).

The regular registered credit hours per semester are between 12 and 19 but it is not allowed to be less than 12 credits, however, in summer semester it ranges between 3 and 9 credit hours. Depending on the completed credit hours the students are classified into 8 levels:

1. F: Freshman, a student who successfully completed less than 31 credit hours.

2. So: Sophomore, a student who successfully completed between 31 and 60 credit hours.

3. J: Junior, a student who successfully completed between 61 and 90 credit hours.

4. Se: Senior, a student who successfully completed more than 90 credit hours.

5. NR: Not registered, perhaps to take care of personal problems, but eventually will return to the system

6. G: Graduated from KU.

7. D: Dropped out or academically dismissed from KU.

8. T: Transferred to another college in KU.

The outcomes (graduates) of KU are considerably less than the incomes (freshmen). This is more visible in the scientific colleges. The attrition occurs from KU and in particular from scientific colleges at a significant percentage. It also happens that the transfer from scientific colleges to art colleges also occurs at a high percentage.

A high proportion of students may stay longer in their course of study for several reasons, especially in the freshman and senior stages. As such, it is necessary to study the average time that a student spends in each level, as well as the probability that a student who has been admitted will graduate or withdraw from each college specifically and generally from KU. A comparative study was conducted between the different colleges and between KU and each of these colleges in order to determine which college is closest to the normal average time. Finally the factors that cause a student to spend 0 increasing numbers of semesters in each level of study were investigated.

Markov analysis is used to investigate the flow process of students in KU. It has been employed in several flow processes (see Wainwright, 2007; Nichols, 2008; Al-Awadhi \& Konsowa, 2007; Bessent \& Bessent, 1980; Kolesat, 1970; Kwak, et al., 1985; Merddith, 1976; McNamara, 1974). Al-Awadhi and Konsowa (2007) studied student flow in the College of Science at KU. Bessent and Bessent (1980) studied the progression process of doctoral students in a university department to avoid undesirable future dissertation overload for supervising professors. Kwak, et al. (1985) were interested in forecasting student enrollment variations for an academic institution. Bessent and Bessent (1980) proposed an enrollment retention model using a Markov process to analyze enrollment rates for overlooked segments of the student population as well as the retention rate for specifying degree programs, rather than just the retention rates for aggregate incoming freshman. Reynolds and Porath (2008) studied absorbing Markov chains to model the academic progress of students attending the University of Wisconsin-Eau Claire over a specific time period.

\section{Methodology}

A random sample of 1,100 students was selected from the office of the Deanship of Admission and Registration. The data pertains to a period of 9 years from the academic years 1996-1997 to 2004-2005. Stratified random sampling was used for the sample collection. The sample size for each college was determined in proportion to the total number of students in each college and the sample from each college was divided into 8 groups proportionally to the number of students in each level defined as: freshmen, sophomore, junior, senior, non-register, graduate, drop out and transfer. Each of these groups was subdivided proportionally according to the departments in the college. Finally a random sample of each of the sub-groups was selected from each college. 
The Conceptual Framework: Markov Chains

Some background concerning the Markov chains is presented, for additional detail; see Kwak, et al. (1985) or Resnick (1994). Consider a finite discrete time homogeneous stochastic process with index set $\mathbb{Z}^{+}=\{0,1$, $2, \ldots\}$; that is, a sequence $\left\{X_{n}: n \in \mathbb{Z}^{+}\right\}$of random variables. As usual the subscript $n$ in $X_{n}$ stands for the time and $X_{n}$ denotes the state of the process at time $n$. If $X_{n} \in S$, then $S$ is called the state space of the stochastic process. The stochastic processes considered here satisfy the Markov property. Given the present state, the future of the process is independent of the past. That is, for $\mathrm{i}, \mathrm{j}, x_{0}, \ldots, x_{n-1} 1 \in \mathrm{S}$,

$$
\begin{aligned}
\mathrm{P}\left(\mathrm{X}_{n+1}\right. & \left.=\mathrm{j} \mid X_{0}=\mathrm{x}_{0}, \ldots, \mathrm{X}_{n-1}=\mathrm{x}_{n-1}, \mathrm{X}_{n}=\mathrm{i}\right) \\
& =\mathrm{P}\left(\mathrm{X}_{n+1}=\mathrm{j} \mid X_{n}=\mathrm{i}\right)=\mathrm{P}_{i j}
\end{aligned}
$$

A stochastic process with this property is called a homogenous Markov chain. The quantity $\mathrm{P}_{\mathrm{ij}}$ stands for the probability of moving from state $i$ to state $j$ in just one transition and all these quantities define the matrix of one-step transition probabilities $P$ :

$$
p=\left[\begin{array}{cccc}
p_{11} & p_{12} & \cdots & p_{1 k} \\
p_{21} & p_{22} & \cdots & p_{2 k} \\
\cdot & \cdot & \cdot & \cdot \\
\cdot & \cdot & \cdot & \cdot \\
\cdot & \cdot & \cdot & \cdot \\
p_{k 1} & p_{k 2} & \cdots & p_{k k}
\end{array}\right]=\left(p_{i j}\right)
$$

where the finite set $\mathrm{I}_{k}=\{1,2, \ldots, \mathrm{k}\}$ is the state space of the Markov chain. The entries $\mathrm{P}_{i j}$ of the matrix P must satisfy: (1) $P_{i j} \geq 0$, (2) $\Sigma_{j} P_{i j}=1, i, j \in I_{k}$. The recurrent state $\mathrm{i}$ is called the absorbing state if $P_{i i}=1$. The transient matrix $\mathrm{P}$ in its canonical form is $p=\left(\frac{I \mid 0}{R \mid Q}\right)$, where $\mathrm{I}$ is the identity matrix corresponding to the absorbing states, 0 is zero matrix, $\mathrm{Q}$ is the restriction of $\mathrm{P}$ to the transient states and $R=\left(P_{k l}: k\right.$ is a transient state and $l$ is an absorbing state. The fundamental matrix $\mathrm{N}$ is defined to be ( $I-$ $Q)^{-1}$ where it is known that the matrix (I - Q) is invertible. Let $N_{i j}$ be the $\mathrm{ij}^{\text {th }}$ entry of $\mathrm{N}$, then $N_{i j}$ is the mean number of visits to state j having started at state i. If $M_{i}$ refers to the mean absorption time starting at state $\mathrm{i}$, then $M_{i}=\sum_{j \in Q} N_{i j}$; that is $M=N \xi$, where $\xi$ is a vector all of its components are 1's. Another quantity of interest is the probability $U_{i j}$ that the chain starting in a transient $i$ will end up in the absorbing state $\mathrm{j}$. If $U$ stands for the matrix with entries $U_{i j}$, then $U=N R$.

\section{Data Analysis and Transition Probabilities}

The frequency table of the university as a whole is compared with the frequency table of the university excluding the data of the Medical Sciences colleges. Because the study time for the Medical Sciences colleges is much longer than other colleges, it was thought that this may affect the analysis and the results may not be accurate. However, it was found that when analyzing the data with and without these colleges, the results are very close to each other (due to shortage of space, the comparison analysis is not shown here). This is most likely due to the sample size of the medical sciences colleges, which is small (about 45 cases) compared with the samples of other colleges.

\section{Results}

The data from each college was studied and the corresponding analysis is conducted. Table 1 displays a $(7 \times 7)$ frequency matrix for KU from which the transition probabilities are estimated. The matrix which represents the transition probabilities of remaining in or progressing to another state is referred as $\mathrm{P}$ in its canonical form and is presented in Table 2 . The table shows that states $\mathrm{G}$ and $\mathrm{O}$ are considered to be absorbing states while the other states are transient states. Note that the transfer state is considered here as a transient state because the transfer is defined as transferred to 


\section{ALAWADHI \& KONSOWA}

another college within $\mathrm{KU}$, however when each college is analyzed separately the transfer state is considered as an absorbing state.

Note in Table 2 the probability that a freshman student remains in the state itself is 0.62 and the probability of progressing to sophomore is 0.33. For a sophomore student, the probability of progressing to the junior state is 0.41 . The probability that a senior student remains in the same state is high $(0.73)$. This may be attributed to the fact that the normal lifetime for some colleges such as the College of Engineering is more than 4 years and also the fact that the courses at the senior levels are tougher than those of the other levels. The probability of remaining a not registered student for another semester is 0.25 and to move to junior level is 0.22 while moving to other transient states varies between 0.12 and 0.16 .

Proceeding as described, the diagonal elements of the matrix $\mathrm{N}$ represent the average life times that correspond to the transient states of the Markov chain. They are obtained for the levels F, So, J, Se, and NR and are found to be 2.752, 2.333, 2.041, 3.709, and 1.446 respectively. The average life time for a student at each level does not exceed 2.752, which is normal except for the senior level, which is found to be 3.7 semesters. This may
Table 1: Frequency Transition Data

\begin{tabular}{|c|c|c|c|c|c|c|c|}
\cline { 2 - 8 } \multicolumn{1}{c|}{} & F & So & J & Se & NR & G & O \\
\hline F & 1,425 & 754 & 0 & 0 & 61 & 0 & 45 \\
\hline So & 0 & 900 & 672 & 0 & 34 & 0 & 21 \\
\hline J & 0 & 0 & 591 & 577 & 26 & 1 & 10 \\
\hline Se & 0 & 0 & 0 & 1,260 & 7 & 456 & 11 \\
\hline NR & 20 & 21 & 29 & 16 & 33 & 0 & 11 \\
\hline G & 0 & 0 & 0 & 0 & 0 & 457 & 0 \\
\hline O & 0 & 0 & 0 & 0 & 0 & 0 & 100 \\
\hline
\end{tabular}

be attributed to two reasons: (1) many students repeat courses to raise their GPA, and (2) Medical Sciences and Engineering students require more than 4 years to graduate so their senior states would be longer than the other colleges.

Vectors $M$ are calculated and represent the average number of semesters needed to reach an absorbing state (graduate or dropout) starting at any given level. The components of $M$ are: $10.181,7.977,5.829,3.773$ and 7.525 corresponding to the states F, So, J, Se and NR respectively. The probabilities of graduating or dropping out starting at a given level are displayed in Table 3 as matrix $U$.

The probabilities of graduating for freshmen, sophomore, junior, senior and non register levels are $0.86,0.92,0.95,0.98$ and 0.82 respectively. It is observed that the

Table 2: Transition Probability Matrix $P$

$P=$\begin{tabular}{|c|cc|ccccc|}
\hline & $\mathrm{G}$ & $\mathrm{O}$ & $\mathrm{F}$ & $\mathrm{So}$ & $\mathrm{J}$ & $\mathrm{Se}$ & $\mathrm{N} \mathrm{R}$ \\
\hline $\mathrm{G}$ & 1 & 0 & 0 & 0 & 0 & 0 & 0 \\
$\mathrm{O}$ & 0 & 1 & 0 & 0 & 0 & 0 & 0 \\
\hline $\mathrm{F}$ & 0 & 0.02 & 0.624 & 0.330 & 0 & 0 & 0.026 \\
$\mathrm{So}$ & 0 & 0.013 & 0 & 0.553 & 0.413 & 0 & 0.021 \\
$\mathrm{~J}$ & 0 & 0.009 & 0 & 0 & 0.490 & 0.479 & 0.022 \\
$\mathrm{Se}$ & 0.263 & 0.006 & 0 & 0 & 0 & 0.727 & 0.004 \\
$\mathrm{~N} \mathrm{R}$ & 0 & 0.085 & 0.153 & 0.162 & 0.223 & 0.123 & 0.254 \\
\hline
\end{tabular}


Table 3: Probability Matrix $U$

$$
U=\left[\begin{array}{cll} 
& G & O \\
F & 0.862 & 0.138 \\
S o & 0.918 & 0.082 \\
J & 0.952 & 0.048 \\
S e & 0.975 & 0.025 \\
N R & 0.821 & 0.179
\end{array}\right]
$$

probability of progressing to graduation increases as a student moves to advanced levels and, as such, decreases for dropping out.

\section{Data from Different Colleges}

The data from each college was analyzed separately. The transition probability matrix and the fundamental matrix were obtained from the corresponding frequency tables. The columns in Table 4 represent the diagonal elements of the probability transition matrices of the corresponding colleges and these diagonal elements provide the probability that a student remains in the same state. It is noted that the probabilities to remain in the same state are generally close to 0.50 .

The columns of Table 5 represent the diagonal elements of $\mathrm{N}$ matrices of the corresponding colleges. As noted, the diagonal elements of matrix $\mathrm{N}$ represent the average times a student spends in a level of study. For many levels, a student spends approximately 2 to 3 semesters in each state before passing to a higher level of study except for senior level, where they may remain more than 3 semesters for some colleges. A freshman student spends on average about 2.5 semesters, except those in the college of Science where about 3.9 semesters are required to make a transition. As the student advances to the senior level, the mean time increases with longest mean time in the colleges of Medical S ciences.

The $M$ vectors for the university colleges represent the average times required to reach an absorbing state (graduate G, drop out $\mathrm{D}$, transfer $\mathrm{T}$ ) starting at a transient state (see Table 6). To reach an absorbing state in many colleges a freshman student takes more than 8 semesters, whereas a senior student takes commonly more than 3 semesters.

Table 4: Probabilities to Remain in the Transient States of Each College

\begin{tabular}{|c|l|l|l|l|l|l|l|l|l|c|}
\cline { 2 - 12 } \multicolumn{1}{c|}{} & Arts & Soc & Law & Bus & Edn & Shar & Sci & Eng & Med & Allied \\
\hline F & 0.56 & 0.59 & 0.61 & 0.55 & 0.55 & 0.53 & 0.71 & 0.59 & 0.50 & 0.60 \\
\hline So & 0.56 & 0.55 & 0.63 & 0.48 & 0.51 & 0.42 & 0.51 & 0.56 & 0.36 & 0.56 \\
\hline J & 0.50 & 0.52 & 0.56 & 0.46 & 0.44 & 0.43 & 0.47 & 0.49 & 0.54 & 0.44 \\
\hline Se & 0.66 & 0.65 & 0.61 & 0.63 & 0.74 & 0.65 & 0.73 & 0.78 & 0.90 & 0.71 \\
\hline N R & 0.16 & 0.43 & 0.43 & 0.15 & 0.18 & 0.17 & 0.31 & 0.29 & 0.33 & 0.00 \\
\hline
\end{tabular}

Table 5: Average Lifetimes of Students in Each Transient State

\begin{tabular}{|c|c|c|c|c|c|c|c|c|c|c|}
\cline { 2 - 11 } \multicolumn{1}{c|}{} & Arts & Soc & Law & Bus & Edn & Shar & Sci & Eng & Med & Allied \\
\hline F & 2.3 & 2.5 & 2.6 & 2.3 & 2.3 & 2.2 & 3.9 & 2.5 & 2.0 & 2.3 \\
\hline So & 2.4 & 2.3 & 2.7 & 2.1 & 2.1 & 1.8 & 2.2 & 2.4 & 1.6 & 2.3 \\
\hline J & 2.1 & 2.2 & 2.4 & 1.9 & 1.8 & 1.9 & 1.9 & 2.1 & 2.2 & 1.9 \\
\hline Se & 2.9 & 2.9 & 2.6 & 2.8 & 3.9 & 3.0 & 3.8 & 4.6 & 10.4 & 3.5 \\
\hline N R & 1.3 & 1.8 & 1.8 & 1.3 & 1.3 & 1.3 & 1.7 & 1.5 & 1.6 & 1.1 \\
\hline
\end{tabular}




\section{ALAWADHI \& KONSOWA}

On average, students in the colleges of Medical Sciences, Science and Engineering spend more time in the system to reach an absorbing state. This is due to the facts that the courses in these colleges are difficult and also because the number of credits for the colleges of Engineering and Medical Sciences is large compared to other colleges. In addition, it could be due to the repetition of the courses by the students in acquiring better GPAs, as in the case of the college of Science. A student with a low GPA finds it difficult to pass the core courses offered in the college. Thus many students repeat these courses to improve their GPA. At the senior level, a student from the college of Medical Sciences spends comparatively more time in practical classes (almost 5 years are needed to qualify them for professional careers).

At this stage, the U-matrices for the 10 colleges are calculated. The entry $u_{i j}$ of a $\mathrm{U}$ matrix represents the probability of absorption at state $\mathbf{j}$ having started at state $\mathbf{i}$. For the purpose of comparison, the entries of U-matrices are classified into three matrices corresponding to the three absorbing states: graduate, drop out, and transfer. (See Tables 7, 8 and 9.) For example, the first column of Table 7 stands for the probability of graduation of an arts' student enrolled in the respective levels F, So, J, Se and NR.

Table 6: Average Time Needed to Reach an Absorbing State

\begin{tabular}{|c|c|c|c|c|c|c|c|c|c|c|}
\cline { 2 - 11 } \multicolumn{1}{c|}{} & Arts & Soc & Law & Bus & Edn & Shar & Sci & Eng & Med & Allied \\
\hline F & 7.66 & 9.45 & 10.37 & 8.08 & 9.46 & 7.69 & 8.20 & 10.1 & 15.30 & 8.15 \\
\hline So & 7.10 & 7.32 & 7.94 & 6.53 & 7.77 & 6.49 & 5.70 & 8.70 & 13.60 & 6.73 \\
\hline J & 5.07 & 5.15 & 5.20 & 4.74 & 5.73 & 5.03 & 5.43 & 6.70 & 12.60 & 5.44 \\
\hline Se & 3.04 & 2.88 & 2.72 & 2.83 & 3.87 & 3.24 & 3.77 & 4.70 & 10.43 & 3.46 \\
\hline N R & 5.91 & 6.31 & 5.71 & 6.72 & 8.48 & 5.48 & 7.61 & 6.80 & 15.90 & 6.27 \\
\hline
\end{tabular}

Table 7: Probabilities of Reaching the Graduate State $G$ for the 10 Colleges at KU

\begin{tabular}{|c|c|c|c|c|c|c|c|c|c|c|}
\cline { 2 - 12 } \multicolumn{1}{c|}{} & Arts & Soc & Law & Bus & Edn & Shar & Sci & Eng & Med & Allied \\
\hline F & 0.60 & 0.91 & 0.98 & 0.80 & 0.91 & 0.77 & 0.37 & 0.77 & 0.93 & 0.69 \\
\hline So & 0.79 & 0.95 & 1.00 & 0.91 & 0.99 & 0.89 & 0.49 & 0.88 & 0.95 & 0.81 \\
\hline J & 0.85 & 0.98 & 1.00 & 0.95 & 1.00 & 0.96 & 0.78 & 0.94 & 1.00 & 0.99 \\
\hline Se & 0.90 & 1.00 & 1.00 & 0.98 & 1.00 & 0.96 & 0.94 & 0.99 & 1.00 & 1.00 \\
\hline N R & 0.72 & 0.98 & 1.00 & 0.81 & 0.97 & 0.85 & 0.45 & 0.62 & 0.94 & 0.95 \\
\hline
\end{tabular}

Table 8: Probabilities of Reaching the Drop -out State $O$ for the 10 Colleges at KU

\begin{tabular}{|c|c|c|c|c|c|c|c|c|c|c|}
\cline { 2 - 12 } \multicolumn{1}{c|}{} & Arts & Soc & Law & Bus & Edn & Shar & Sci & Eng & Med & Allied \\
\hline F & 0.19 & 0.05 & 0.02 & 0.07 & 0.01 & 0.08 & 0.26 & 0.20 & 0.07 & 0.11 \\
\hline So & 0.18 & 0.05 & 0 & 0.03 & 0 & 0.04 & 0.17 & 0.10 & 0.05 & 0.05 \\
\hline J & 0.15 & 0.02 & 0 & 0.03 & 0 & 0.04 & 0.09 & 0.04 & 0 & 0 \\
\hline Se & 0.09 & 0 & 0 & 0.02 & 0 & 0.04 & 0.03 & 0.01 & 0 & 0 \\
\hline N R & 0.26 & 0.02 & 0 & 0.04 & 0 & 0.12 & 0.29 & 0.37 & 0.06 & 0.01 \\
\hline
\end{tabular}


MARKOV CHAIN ANALYSIS AND STUDENT ACADEMIC PROGRESS

Table 9: Probability of Reaching the Transfer State $T$ for the 10 Colleges at KU

\begin{tabular}{|c|c|c|c|c|c|c|c|c|c|c|}
\cline { 2 - 12 } \multicolumn{1}{c|}{} & Arts & Soc & Law & Bus & Edn & Shar & Sci & Eng & Med & Allied \\
\hline F & 0.21 & 0.05 & 0 & 0.13 & 0.08 & 0.15 & 0.34 & 0.03 & 0 & 0.19 \\
\hline So & 0.04 & 0 & 0 & 0.07 & 0.01 & 0.06 & 0.34 & 0.02 & 0 & 0.15 \\
\hline J & 0 & 0 & 0 & 0.02 & 0 & 0 & 0.14 & 0.02 & 0 & 0 \\
\hline Se & 0 & 0 & 0 & 0 & 0 & 0 & 0.03 & 0 & 0 & 0 \\
\hline N R & 0.02 & 0 & 0 & 0.15 & 0.02 & 0.01 & 0.27 & 0.01 & 0 & 0.04 \\
\hline
\end{tabular}

Table 7 shows that a student at a junior state attains the absorbing state $\mathrm{G}$ with an average probability above 0.94. The probability of graduation increases as the student moves to the senior level. For the colleges of Law, Social Science, Education, Allied Health and Medical Sciences, it is assumed that the senior students strive hard to graduate from KU.

The probability of reaching the graduating state from the freshman level is comparatively low for the college of Science (0.37); this may be due to the difficult courses in the college of Science and also to the fact that most of the students admitted to the college of Science have the lowest high school grades and are usually competitive students. Also, it is noted that the probability of graduation of students in the NR state is very low for the college of Science, thus, it is estimated that only $45 \%$ of the students who are non-registered will re-enter the system and complete their course of study.

The chances of dropping out of the system from the first levels of the colleges of Science and Arts are comparatively high. This may be due to probations. KU regulations do not allow a student to continue her/his study when she/he reaches 4 probations. Similarly, the probability that a student drops out after reaching the non registered state is considerably high for Arts, Sciences and Engineering students.

The percentage of students transferring from Science to other colleges is relatively high for freshman, sophomore, non register and junior states. Similarly the percentage of students transferring from the freshman and sophomore states in the Allied states. The probability of transferring is zero for students from the Law and Medical Sciences colleges and this can be attributed to the fact that once a student is enrolled in these annual systems, she/he cannot transfer to other colleges where all the credits she/he passed cannot be transferred to other semester system colleges.

If the transient states freshman, sophomore, junior, senior, non registered are respectively assigned the numbers $4,5,6,7$ and 8 , then the mean number of semesters the chain remains in each of them after it is entered (including the entering step) are calculated

$$
E_{i}\left(r_{i}\right)=\sum_{k=0}^{\infty} P_{i i}^{k}=\frac{1}{1-p_{i i}} ; i=4,5,6,7,8,
$$

(see Table 10). It is noted that $E_{i}\left(r_{i}\right)$ refers to the mean continuous stay in state $i$ once it is entered, whereas, $N_{i i}$ stands for the mean number of visits to state $i$ regardless of any departures from $i$. The slight differences between the entries of Tables 5 and 10 are explained by the small transition probabilities to the state NR in the transition matrix of Table 2.

The mean number of changes of a state in an absorbing chain can be calculated by setting $P_{i i}=0$ for every transient state in the transition matrix $P$ and then dividing each row by its row sum to obtain $P^{*}$. The $i^{\text {th }}$ component of the new vector $M^{*}$ gives the mean number of changes of the state $i$ for the original process. The $i^{\text {th }}$ component in the two vectors $M$ and $M^{*}$ may differ slightly if the repetitions of the states on the path from $i$ to absorption is rare; otherwise, the two vectors 


\section{ALAWADHI \& KONSOWA}

may differ significantly. From the matrix $P^{*}$ of the different colleges, the vectors $M^{*}=N^{*} \xi$ are calculated and are shown in Table 11.

As noted, the significant differences between some of the components of $M$ and $M^{*}$ are interpreted by repeating courses and staying longer in some levels. The small values corresponding to the freshmen and sophomore levels in the college of Science depicts the occurrence of dropping out and transferring in these two levels.

Comparison between Scientific and Art Colleges

To compare the scientific and arts colleges, the colleges were divided into 2 groups: (1) Scientific colleges: Science, Engineering and Allied Health, and (2) Art colleges: Arts, Social Sciences and Sharia \&
Islamic Studies. The College of Medical $\mathrm{S}$ cience which has a lengthier course schedule, the College of Law which is a professional course and the Colleges of Education and Business administration which have a mixture of science and art students have all been excluded from the groupings. Mean lifetimes in each state for the scientific and art colleges are shown in Table 12. It is clear that the lifetimes of students in scientific colleges are longer than that of art colleges, especially at the senior levels. The vector $M$ as represented in Table 13 gives the average time spent by a student in the system before reaching one of the absorbing states. It is clear that the scientific student needs more time to reach one of the observing states $(\mathrm{G}, \mathrm{O}, \mathrm{T})$. This may be due to the difficulty of the study in their colleges compared to art colleges. Going through the details of these absorbing states, $U$ matrices are calculated.

Table 10: Average Number of Semesters the Chain Remains in Transient States

\begin{tabular}{|c|c|c|c|c|c|c|c|c|c|c|}
\cline { 2 - 11 } \multicolumn{1}{c|}{} & Arts & Soc & Law & Bus & Edn & Shar & Sci & Eng & Med & Allied \\
\hline E4(r4) & 2.28 & 2.47 & 2.59 & 2.24 & 2.24 & 2.14 & 3.52 & 2.41 & 2.00 & 2.5 \\
\hline E5(r5) & 2.28 & 2.22 & 2.73 & 1.93 & 2.05 & 1.73 & 2.04 & 2.25 & 1.6 & 2.3 \\
\hline E6(r6) & 2.02 & 2.12 & 2.32 & 1.83 & 1.79 & 1.77 & 1.87 & 1.98 & 2.17 & 1.81 \\
\hline E7(r7) & 2.96 & 2.88 & 2.57 & 2.71 & 3.87 & 2.83 & 3.77 & 4.6 & 10.38 & 3.45 \\
\hline E8(r8) & 1.19 & 1.75 & 1.75 & 1.18 & 1.2 & 1.2 & 1.44 & 1.4 & 1.5 & 1 \\
\hline
\end{tabular}

Table 11: $M^{*}$ Vectors: Average Number of State-Changes Before Absorption

\begin{tabular}{|c|c|c|c|c|c|c|c|c|c|c|}
\cline { 2 - 11 } \multicolumn{1}{c|}{} & Arts & Soc & Law & Bus & Edn & Shar & Sci & Eng & Med & Allied \\
\hline F & 3.29 & 3.95 & 4.1 & 3.79 & 3.84 & 3.73 & 2.98 & 3.8 & 3.9 & 3.38 \\
\hline So & 3.02 & 3.09 & 3.16 & 3.08 & 3.05 & 3.17 & 2.40 & 3.1 & 3.0 & 2.76 \\
\hline J & 2.09 & 2.09 & 2.15 & 2.13 & 2.04 & 2.27 & 2.04 & 2.15 & 2.00 & 2.13 \\
\hline Se & 1.03 & 1.00 & 1.07 & 1.06 & 1.00 & 1.22 & 1.00 & 1.10 & 1.00 & 1.00 \\
\hline N R & 2.96 & 2.79 & 2.61 & 3.55 & 3.77 & 2.91 & 3.29 & 2.8 & 4.5 & 3.00 \\
\hline
\end{tabular}

Table 12: Mean Lifetime in Each State for Scientific and Art Colleges

\begin{tabular}{|c|c|c|}
\cline { 2 - 3 } \multicolumn{1}{c|}{} & Science & Art \\
\hline F & 3.20 & 2.31 \\
So & 2.25 & 2.22 \\
J & 1.99 & 2.09 \\
Se & 4.20 & 2.98 \\
N R & 1.53 & 1.36 \\
\hline
\end{tabular}

Table 13: Average Time Required Reaching One of the Absorbing States

\begin{tabular}{|c|c|c|}
\cline { 2 - 3 } \multicolumn{1}{c|}{} & Science & Art \\
\hline F & 8.8 & 8.1 \\
So & 6.9 & 7.0 \\
J & 6.0 & 5.1 \\
Se & 4.3 & 3.1 \\
N R & 7.1 & 5.9 \\
\hline
\end{tabular}


The $U$ matrices display the probabilities of reaching the absorbing states $\mathrm{G}, \mathrm{O}$ and $\mathrm{T}$ are as follows

$$
\begin{aligned}
\mathrm{U}_{\mathrm{Sci}} & =\left[\begin{array}{clll} 
& \mathrm{G} & \mathrm{O} & \mathrm{T} \\
\mathrm{F} & 0.554 & 0.221 & 0.225 \\
\mathrm{So} & 0.680 & 0.130 & 1.190 \\
\mathrm{~J} & 0.879 & 0.055 & 0.066 \\
\mathrm{Se} & 0.972 & 0.015 & 0.013 \\
\mathrm{NR} & 0.589 & 0.294 & 0117
\end{array}\right] \text {; } \\
\mathrm{U}_{\text {Art }} & =\left[\begin{array}{clll}
\mathrm{G} & \mathrm{O} & \mathrm{T} \\
\mathrm{F} & 0.701 & 0.137 & 0.162 \\
\mathrm{~J} & 0.849 & 0.120 & 0.032 \\
\mathrm{Se} & 0.937 & 0.098 & 0.001 \\
\mathrm{NR} & 0.803 & 0.185 & 0.0012
\end{array}\right]
\end{aligned}
$$

It is clear that - except for the senior state - the probability of graduation is higher for the art students than for the scientific students. The students in the NR state show a tendency to drop out rather than to transfer and the probabilities are higher in both cases for the Science students than for the Art students.

Graduation Process

An interesting use of the conditional probability for absorbing Markov chains is the following: Assume that for an absorbing chain, we start in a non-absorbing state and computing all the probabilities relative to the hypothesis that the process ends in a given absorbing state, for example, $s_{1}$. Then it is possible to obtain a new absorbing chain with a single absorbing state $s_{1}$. The nonabsorbing states will be as before, except that we have new transition probabilities. Computing these probabilities is as follows: Let $A$ be the event that the chain is absorbed in the state $s_{1}$. If $s_{i}$ is a non-absorbing state then the transition probabilities of the new process are

$$
\begin{aligned}
p_{i}\left(X_{1}\right. & \left.=s_{j} \mid A\right)=\frac{p_{i}\left(A \mid X_{1}=s_{j}\right) p_{i}\left(X_{1}=s_{j}\right)}{p_{i}(A)} \\
& =\frac{p_{j}(A) p_{i j}}{p_{i}(A)}
\end{aligned}
$$

where $p_{j}(A)$ is the occurrence probability of the event $A$ starting at state $s_{j}$ and $p_{i j}$ is the one step transition probability from state $s_{i}$ to state $s_{j}$. Using traditional notation, the equation above can be written as $\hat{p}_{i j}=\frac{u_{j 1} p_{i j}}{u_{i 1}}$, where $\hat{p}_{i j}$ stands for the elements of the new transition matrix. The canonical form of the new transition matrix $\hat{P}$ is $\hat{P}=\left(\begin{array}{ll}\hat{I} & \hat{0} \\ \hat{R} & \hat{Q}\end{array}\right)$.

The elements of submatrix $\hat{R}$ for a transient state $s_{i}$ are given by $\hat{p}_{i 1}=\frac{p_{i 1}}{u_{i 1}}$. That is $\hat{R}=\left[\frac{p_{i 1}}{u_{i 1}}\right]$. If $U_{0}$ is the diagonal matrix with diagonal elements $u_{j 1}{ }^{\prime} s$ for the non-absorbing states $s_{j}{ }^{\prime} s$, then $\hat{\mathrm{Q}}=\mathrm{U}_{0}^{-1} \mathrm{QU}_{0}$, from which $\hat{Q}^{n}=U_{0}^{-1} Q^{n} U_{0}$. As such $\hat{N}=I+\hat{Q}+\hat{Q}^{2}+\ldots=U_{0}^{-1}\left(\sum_{n=0}^{\infty} Q^{n}\right) U_{0}=U_{0}^{-1} N U_{0}$, and $\hat{M}=\hat{N} \eta$ (Kemeny \& Snell, 1970). Using the original transition matrix in its canonical form in Table 2, the matrix $\mathrm{N}=(I-Q)^{-1}$ can be computed. Also, the first column of the $U$-Matrix (Table 3) constitutes the diagonal elements of the diagonal matrix $U_{0}$. In which case, the matrix $\hat{N}=U_{0}^{-1} N U_{0}$ would be:

$$
\hat{N}=\left[\begin{array}{cccccc} 
& F & S o & J & S e & N R \\
F & 2.508 & 2.121 & 1.971 & 3.693 & 0.210 \\
S o & 0.043 & 2.204 & 1.996 & 3.688 & 0.120 \\
J & 0.024 & 0.044 & 2.015 & 3.692 & 0.066 \\
S e & 0.006 & 0.011 & 0.018 & 3.692 & 0.016 \\
N R & 0.511 & 0.961 & 1.592 & 3.695 & 1.423
\end{array}\right]
$$




\section{ALAWADHI \& KONSOWA}

From which the vector $\hat{M}$ that determines the average number of semesters required for graduation starting from the different levels of study becomes

$$
\hat{M}=\left[\begin{array}{cc}
F & 10.503 \\
S o & 8.052 \\
J & 5.842 \\
S e & 3.744 \\
N R & 8.182
\end{array}\right]
$$

Conclusion

The lifetimes of a student in different levels varies depending on the colleges. A freshman student remains a freshman for an average of 2 to 3 semesters except in the College of Science where it is about 4 semesters. For the second state, sophomore, the life times in different colleges again varies from about 2 to 3 semesters. Junior students spend less time, less than 2 semesters for several colleges. At senior levels where the courses are comparatively more difficult, the life times vary significantly.

For students in the colleges of Medical Sciences, Engineering, Education and Science, the life times are comparatively high. The most common reasons for the lengthy life times are:

1) Most of the students take preliminary noncredit courses in English, Mathematics and Chemistry (these courses are compulsory if a student did not pass the university aptitude test once she/he is enrolled in scientific colleges). After a student registers in these intensive courses, $\mathrm{she} / \mathrm{he}$ is not allowed to register in the same semester more than 3 credit hours.

2 ) The regular credit hours a student should be registered for should be between 15 and 19 credit hours but the actual average registered credit hours for a student in KU is calculated to be about 13 credit hours. This low registered number of credit hours delays the student graduation and prolongs the time of the study.
3) The minimum GPA for graduation is 2.00 and many students cannot achieve this GPA to graduate so they repeat some courses with a grade less than $\mathrm{C}$ to increase their overall GPA.

4) Being a Non Register stude n t for some semesters delays graduation.

5) Each college has its own rules and bylaws for transferring, such as taking certain courses and requiring a certain GPA. When a student is not satisfied or not interested in the college she/he is admitted to, she/he may decide to transfer to another college and, as such, her/his case should meet the bylaws of that college. This increases the time period of the study.

The overall analysis of the results can be summarized as follows. Three states: graduation, dropping out, and transferring are classified in this analysis as absorbing states. Among the freshman students in the colleges of Arts, Sharia (Islamic studies), Business Administration, Engineering, Allied Health and Science, the graduation percentages range between $60 \%$ and $80 \%$, while that of Social Sciences, Law, Education, and Medical Sciences range between $90 \%$ and $98 \%$. For $\mathrm{KU}$ as a whole, the graduation percentage is about $77 \%$. Similarly the probability of graduation of a student at the sophomore level ranges between 0.49 and 1 while the overall percentile is $86.6 \%$ for KU. Thus, an increased probability of graduation is observed as the student moves to the higher levels. For students who are in the junior and senior states, the probabilities of graduation are 0.95 and 0.98 , respectively. The most remarkable point is that, for the sophomore, junior and senior students of the Law College, the probability of graduation is 1 which ensures that once the student reaches the sophomore state, he/she is certain of completing successfully her/his course of study.

Considering the students in the nonregistered state in Table 7 , the overall graduation percentage is only $83 \%$, and the colleges percentages vary between $45 \%$ (for the Science College) to $100 \%$ (for Law 
College). It was found that the rate for the dropout state is very small. This is obvious when the graduation rate is high in each state. Thus, even though the students spend more time in the system, above $85 \%$ of them will reach graduation.

Comparing between colleges on the basis of the student lifetime was also investigated. For the Colleges of Sharia \& Islamic study, Education and Allied health, students in the states of freshmen, sophomore and junior have approximately 2 semesters as their lifetimes which increase to approximately 3 semesters at the senior states. Students who belong to the colleges of Law, Arts, Social Sciences and Business Administration have lifetimes of about 3 semesters. For the College of Medical Sciences, the freshmen and junior students have normal lifetimes like other colleges of about 2 semesters and are decreasing in sophomore level, whereas the senior students have much longer period. In the Engineering College a student spends about 4.6 semesters in the senior state. For the college of Science, the mean lifetime varies from 2 to 4 semesters in the different stages of the study.

In comparing the mean lifetimes in the system for science and art colleges, it was found that a student in the scientific colleges stays on average 3.2 semesters in the freshmen state while in the arts colleges a student stays on average only 2.3 semesters. This lengthy lifetime in the scientific colleges was observed for each of the states. This implies that the average time that a student spends in the system is more than that in the art colleges (see Tables 2 and 3). This result is expected and agreeable because the core courses of the scientific colleges are more difficult than those of the art colleges.

It was also found that a freshmen student in the scientific colleges stays on average about 8.8 semesters before reaching an absorbing state. Whereas in the art colleges a freshmen student stays on average about 8.1 semesters. This confirms the above inference. Comparing the probabilities of attaining the stable absorbing states, it was found that the students of scientific colleges have less probability of graduating than the students in the art colleges. As such, the probability of dropping out is higher for the scientific students than for the art students.

To avoid such situations, KU should consider necessary actions to reduce drop out from the scientific colleges. Options may include raising the minimum high school grades for university admission or giving a counseling course for students at the time of admission to help students reduce strain in their studies. The average number of registered credit hours for a student in each semester should be between 15 and 19. At the same time students must avoid the conflict in exams schedule as well as the timing problem between lectures offered at different campus locations. Sections must be opened according to the number of students in each level. Levels should not be classified according to the number of credits but according to the kind of courses.

\section{References}

Al-Awadhi, S. \& Konsowa, M. (2007). An Application of Absorbing Markov Analysis to the Student Flow in Kuwait University. Kuwait Journal of Science and Engineering, 34(2A), 77-89.

Bessent, E.W., \& Bessent, A. W. (1980). Student flow in a university department: Results of Markovian analysis. Interfaces, 3743.

Kolesat, P. (1970). A Markovian model for hospital admission scheduling. Management Science, 16, 384-396.

Kemeny, J. G., \& Snell, J. L. (1970). Finite Markov chains. Princeton, NJ: D.Ban Mostrand Company, Inc.

Kwak, N. K., Brown, R. \& Schniederjans, M. J. (1985). A Markov analysis of estimating student enrollment transition in a trimester institution. SocioEconomic Planning Science, 20(5), 311-318.

Merddith, J. (1976). Selecting optimal training programs in a hospital for the mentally retarded. Operations Research, 24, 899-915.

Mc Namara, J. F. (1974). Markov chain theory and technological forecasting. In Futurism in Education, S. P. Hendey \& J. R.Yates (Eds.). Berkeley, CA: Mc Cutchan. 


\section{ALAWADHI \& KONSOWA}

Nicholls, M. (2008). Short term prediction of student numbers in the Victorian secondary education system. Australian and New Zealand Journal of Statistics, 24(2), 179190.

Resnick, S. I. (1994). Adventures in stochastic processes. Boston, MA: Birkhauser.

Reynolds, D., \& Porath, J. (2008). Markov chains and student academic progress. Unpublished manuscript, Department of Mathematics, University of Wisconsin-Eau Claire, USA.
Wainwright, P. (2007). An enrollment retention study using a Markov model for a regional state university campus in transition. Master thesis, Department of Mathematical sciences, Indiana University, USA, 2007. 